\title{
Emergency internal iliac artery ligation: a conservative lifesaving procedure
}

\author{
Y. M. Kabadi*, Harsha B.
}

Department of Obstetrics \& Gynaecology, Karnataka Institute of Medical Sciences, Hubli, Karnataka, India

Received: 17 July 2015

Accepted: 14 August 2015

*Correspondence:

Dr. Y. M. Kabadi,

E-mail: omkabadi@gmail.com

Copyright: () the author(s), publisher and licensee Medip Academy. This is an open-access article distributed under the terms of the Creative Commons Attribution Non-Commercial License, which permits unrestricted non-commercial use, distribution, and reproduction in any medium, provided the original work is properly cited.

\section{ABSTRACT}

Background: Internal iliac artery ligation (IIAL) is a surgical approach which causes a drop in arterial pressure and virtual elimination of the Trip-hammer effect and also preserves fertility. The objective was to study the role of IIAL in arresting and preventing postpartum hemorrhage (PPH).

Methods: A retrospective case series involving examination of the files of all the women who had Internal iliac artery ligation between June 2013 and May 2015 in the department of Obstetrics and Gynecology, Karnataka Institute of Medical Sciences, Hubli.

Results: Out of the 15 women who underwent IIAL, 14(93.3\%) had therapeutic IIAL and 1(6.67\%) had prophylactic IIAL. Associated procedures like B-Lynch sutures, ovarian a. ligation and uterine a. ligation were performed before the decision for IIAL. Hysterectomy was performed in 5 cases to arrest hemorrhage (33.3\%). Two woman died inspite of IIAL and subtotal hysterectomy due to uncontrolled PPH. No patient suffered pelvic organ injury or ischaemic complications.

Conclusions: Bilateral ligation of Internal Iliac artery is a safe, rapid and effective way of treating PPH. Early resort to IIAL prevents hysterectomy in women with atonic PPH.

\section{INTRODUCTION}

Classically, after the termination of third stage of labour, bleeding more than $500 \mathrm{ml}$ is defined as postpartum hemorrhage (PPH). ${ }^{1}$ Generally, abnormal postpartum bleeding not intervened in due time are responsible for $25 \%$ of maternal morbidities, which rise to $60 \%$ in developing countries. ${ }^{2} \mathrm{PPH}$ is one of the five leading causes of maternal mortality worldwide. Another issue is an increase in chronic morbidities like renal failure, respiratory tract problems and severe anaemia. ${ }^{3}$

Various surgical techniques have been described in PPH patients refractory to massage and uterotonic therapy. Uterine compression sutures, bilateral uterine or internal iliac artery ligation and as a last resort subtotal or total hysterectomy can be performed. ${ }^{1}$
Among them, Internal iliac artery ligation (IIAL) is a surgical approach which causes a drop in arterial pressure and virtual elimination of the Trip-hammer effect and also preserves fertility. ${ }^{4}$ It is not used routinely due to the disadvantages like careful dissection of the retro peritoneum, closeness of the ureter to the iliac vessels and inadvertent ligation of the external iliac artery. In this article, we have presented the efficacy of IIAL in arresting and preventing $\mathrm{PPH}$ as well as in preserving uterus.

\section{METHODS}

The study was carried out as a retrospective controlled study of those who underwent Internal Iliac artery ligation from June 2013 to May 2015 in Karnataka Institute of Medical Sciences, Hubli, India, which is a 
tertiary centre in high-risk obstetrics. Obstetrical and demographic characteristics of the patients including age, parity, risk factors, duration of the operation and complications, blood loss and transfusion, hospital stay, morbidity- mortality information were recorded.

\section{Surgical technique}

Internal iliac artery was approached in our procedures in two ways:

By opening the peritoneum between the Round ligament and the ovarian ligament and approaching the bifurcation Common iliac artery.

By direct incision of the peritoneum over the bifurcation of the common iliac arteries. In both the ways, Ureter was retracted medially and injury to the internal iliac veins was avoided. The artery was ligated using 1-0 vicryl using two ties placed firmly and gently $0.5 \mathrm{~cm}$ apart and $1-1.5 \mathrm{~cm}$ below the bifurcation. Femoral and Dorsalis pedis arteries were palpated for pulsations to rule out inadvertent ligation of External iliac artery.

\section{RESULTS}

In the study of two years, Internal Iliac artery ligations were done in 15 cases to control serious obstetrical hemorrhage. The risk factors associated with patients who underwent IIAL as listed in table 1.

Table 1: Obstetric risk factors in patients who had IIAL.

\begin{tabular}{|ll|}
\hline PIH & $5(33.3 \%)$ \\
\hline Prior CS/ Prior scar & $3(20 \%)$ \\
\hline Forceps delivery & $2(13.3 \%)$ \\
\hline Anaemia & $3(20 \%)$ \\
\hline Placenta praevia & $2(13.3 \%)$ \\
\hline Abruption placenta & $1(6.6 \%)$ \\
\hline
\end{tabular}

Table 2: Indications of IIAL.

\begin{tabular}{|ll|}
\hline Uterine atony & $9(60 \%)$ \\
\hline Placenta praevia & $2(13.3 \%)$ \\
\hline Abruption placentae & $1(6.6 \%)$ \\
\hline Broad lig. Hematoma & $1(6.6 \%)$ \\
\hline Uterine rupture & $2(13.3 \%)$ \\
\hline
\end{tabular}

Table 3: Associated procedures.

\begin{tabular}{|ll|}
\hline Subtotal Hysterectomy & $5(33.3 \%)$ \\
\hline B-Lynch sutures & $5(33.3 \%)$ \\
\hline Uterine a. ligation & $3(20 \%)$ \\
\hline Ovarian a. ligation & $2(13.3 \%)$ \\
\hline None & $5(33.3 \%)$ \\
\hline
\end{tabular}

Associated procedures like hysterectomy, B-lynch, uterine and ovarian a. Ligation were done and the statistics are tabulated in Table 3.5 cases $(33.3 \%)$ needed only IIAL to control PPH. 2 (13.3\%) of 15 cases died.

\section{DISCUSSION}

In our study, the efficacy of bilateral internal iliac artery ligation performed with the indication of serious obstetrical bleeding was detected to be $86.7 \%$. We didn't encounter any procedure-related major complications which were reported in the literature such as major vessel and ureter injury or inadvertent ligation of the external iliac artery. ${ }^{5}$ Two patients died on day 1 within $2-3$ hours after the procedure, one due to central placenta previa and other due to DIC.

In their recently conducted study including 58 patients, Unal et al. reported effectiveness of the method as 87.9 percent. ${ }^{6}$ Similarly, in their review of the results of retrospective studies encompassing 52 patients who had undergone internal artery ligation, Chelli et al indicated a $82.45 \%$ success rate. ${ }^{7}$ Within the frame of literature findings, and results of our study, we think that BIIAL is a life-saving method with smaller number of side effects in obstetrical bleeding refractory to medical treatment.

Following BIIAL, uterine arterial pressure drops with virtual elimination of the trip-hammer effect. The average decrease being $14 \%$ with the opposite side, $77 \%$ with the same side and $85 \%$ with both sides ligated. ${ }^{8,9}$ On the other hand, owing to the presence of collaterals between peripheral and central segments of internal iliac artery, peripheral and aortic branches, uterine artery and subcutaneous abdominal, ovarian, and renal arteries, development of uterine and pelvic necrosis is prevented. ${ }^{10}$ Spontaneous birth rate after BIIAL was reported as $51.7 \%$, and a decrease in uteroplacental blood was not asserted during pregnancies of these cases. ${ }^{11,12}$ Since BIIAL requires more expertise than a routine obstetric surgery, internal iliac artery ligation is not preferred by many obstetricians and gynecologists for the management of postpartum bleeding.

Review of the literature shows serious intraoperative complications such as injury to the internal iliac vein or ureter during ligation of internal iliac artery and related mortality, inadvertent ligation of external iliac artery, post procedural vesical necrosis, development of perineal and gluteal necrosis. ${ }^{5}$ To avoid these complications before ligation of the artery, observation of external, and common iliac arteries, retraction of the ureter medially from the operation field, and ligation of the artery distal to its posterior branches are recommended. To this end, artery should be ligated at least $3 \mathrm{~cm}$ distal to the bifurcation site. In our study, we did not encounter any serious complications cited in the literature. 


\section{CONCLUSIONS}

In conclusion, internal iliac artery ligation is an easily applicable, safe and effective method in experienced hands for the management of life threatening obstetrical bleeding such as postpartum atony. Before hysterectomy, in order to control life threatening intractable postpartum bleeding especially in young women with lower parities, it should be tried because it is not costly and does not required complex equipment with superior advantages such as scarcity of complications and preservation, and maintenance of fertility.

Funding: No funding sources

Conflict of interest: None declared

Ethical approval: The study was approved by the Institutional Ethics Committee

\section{REFERENCES}

1. Ferrazzani S, Guariglia L, Draisci G, Sorrentino L, De Stefano V, D'Onofrio G et al. Postpartum hemorrhage. Minerva Gynecol. 2005;57(2):111-29.

2. Geller SE, Adams MG, Miller S. A continuum of care model for postpartum hemorrhage. Int J Fertil Women's Med. 2007; 52(2-3):97-105.

3. Leung NY, Lau AC, Chan KK, Yan WW. Clinical characteristics and outcomes of obstetric patients admitted to the Intensive Care Unit: a 10-year retrospective review. Hong Kong Med J. 2010;16(1):18- 25.

4. Camuzcuoglu H, Toy H, Vural M, Yildiz F, Aydin $\mathrm{H}$. Internal iliac artery ligation for severe postpartum hemorrhage and severe hemorrhage after postpartum hysterectomy. J Obstet Gynaecol Res. 2010;36(3):538- 43.

5. Atala C, Biotti M. Ligation of internal iliac artery as treatment of hemorrhage in obstetrics and gynecology. Rev Chil Obstet Ginecol. 1993;58(2):119-25.

6. Unal O, Kars B, Buyukbayrak EE, Karsidag AY, Turan C.The effectiveness of bilateral hypogastric artery ligation for obstetric hemorrhage in three different underlying conditions and its impact on future fertility. J Matern Fetal Neonatal Med. 2011;24(10): 1273- 6.

7. Chelli D, Boudaya F, Dimassi K, Gharbi B, Najjar I et al.Hypogastric artery ligation for post-partum hemorrhage. J Gynecol Obstet Biol Reprod (Paris). 2010;39(1):43- 9.

8. Fatu C, Francu D, Puisor M, Fatu CI. Changes in the arterial pressure after ligation of the hypogastric artery. Rev Med Chir Soc Med Nat Iasi. 1996;100(12):149-50.

9. Rajaram P, Raghavan SS, Bupathy A, Balasubramanian SR, Habeebullah S, Umadevi P. Internal iliac artery ligation in obstetrics and gynecology. Ten years experience. Asia Oceania J Obstet Gynaecol. 1993;19(1):71-5.

10. Fatu C, Francu D, Puisor M, Fatu CI. The morphophysiological consequences of experimental ligation of the hypogastric arteries. Rev Med Chir Soc Med Nat Lasi. 1996;100(3-4):177-9.

11. Nizard J, Barrinque L, Frydman R, Fernandez H. Fertility and pregnancy outcomes following hypogastric artery ligation for severe post-partum haemorrhage. Hum Reprod. 2003;18(4):844- 8.

12. Api M, Api O, Yayla M. Fertility after B-Lynch suture and hypogastric artery ligation. Fertil Steril. 2005;84(2):509.

Cite this article as: Kabadi YM, Harsha B. Emergency internal iliac artery ligation: a conservative lifesaving procedure. Int J Reprod Contracept Obstet Gynecol 2015;4:1364-6. 